\title{
Asymmetric Substrate Integrated Waveguide Leaky Wave Antenna with Open Stop Band Suppression and Radiation Efficiency Equalization through Broadside
}

\author{
Rahul AGRAWAL, Pravesh BELWAL, Suresh GUPTA \\ Dept. of ECE, DIT University, Mussorrie Diversion road, 248009 Dehradun, India \\ rahul1@dituniversity.edu.in, \{pravesh,Suresh.Chandra.Gupta\}@dituniversity.edu.in
}

Submitted November 17, 2017 / Accepted February 12, 2018

\begin{abstract}
A planar asymmetric substrate integrated waveguide leaky wave antenna is proposed with open stop band suppression and radiation efficiency equalization through broadside for the Ku-band. The stop-band behavior exhibited at broadside in the 1-D periodic structure is significantly reduced using reflection cancellation technique by placing the two slots at a quarter distance within the unit cell. Furthermore, asymmetric technique is applied. The asymmetry is introduced with respect to both axial and transversal axis of the structure so as to match the atbroadside Bloch impedance and off-broadside Bloch impedance. This provides total open stop band suppression and radiation efficiency improvement as well as equalization through broadside. The problem is analyzed with the help of Bloch impedance behavior. For illustration of the above techniques; single slot, double slot and asymmetric designs are developed for the proposed leaky wave antenna. The final asymmetric design after optimization is fabricated. Measured results are almost consistent with the simulation results with complete suppression of open stop band, efficiency improvement and equalization through broadside providing continuous beam scanning from $-32^{\circ}$ to $+27^{\circ}$ with constant gain of $\sim 12.5 \mathrm{dBi}$.
\end{abstract}

\section{Keywords}

Leaky wave antenna, substrate integrated waveguide, open stop band, reflection cancellation, asymmetry, efficiency equalization, broadside

\section{Introduction}

With increasing applications in the areas of broadband wireless communication and radar, planar periodic structures are receiving renewed interests. Leaky wave antennas (LWA) which work on the foundation of travelling waves are essentially composed of transmission line or waveguide sections with a unit cell period $(P)$, wherein a single or multiple radiator elements are placed within the unit cell. LWAs are mainly characterized as uniform and periodic structures. The uniform LWAs radiate power in forward direction while in the case of periodic LWAs power is radiated in both backward and forward direction [1]. Periodic LWA can be realized by periodic loading of the same slots on each unit cell of the LWA and hence leads to a high directivity. A high directivity of the LWA is needed for accurate positioning. The study here is focused on periodic LWAs which are generally known for their high directivity, frequency scanning capability and simple feeding networks [2].

Substrate integrated waveguides (SIW), an alternative platform to conventional rectangular waveguides is being preferred nowadays for their low profile, low cost and light weight features. Various structures of SIW LWAs are available in literature. [3-6]. As already pointed over the last four decades, two major difficulties encountered with this class of antenna are the open stop band (OSB) [7] and the single beam condition [8]. This study is focused on the problem of the OSB. The limited knowledge about the broadside behavior for conventional periodic LWA exists, as the earlier theories developed for these structures treat each element as loading the line individually, instead of viewing the structure in a leaky wave fashion. The OSB is generally the narrow band region in the vicinity of broadside in which leaky-wave radiation is significantly reduced. The techniques proposed in order to solve the problem of OSB in 1-D periodic LWAs ( $n=-1$ harmonic) are reflection cancellation (RC) [9], [10], impedance matching [11], and asymmetric technique [12]. In RC technique, the wave reflected by the first element is nearly cancelled by the wave reflected by the second element at broadside. This technique, however, yields a mitigation but not a complete suppression of the open stopband. On the contrary, asymmetry technique mentioned above not only provides complete OSB closure but also matches the at-broadside Bloch impedance and off-broadside Bloch impedance, providing radiation efficiency equalization through broadside. The asymmetry is also exploited recently for OSB closure and radiation efficiency improvement in the case of Goubau line LWAs [13]. The OSB suppression in periodic LWA can also be achieved by making use of the concept of composite right/left-handed (CRLH) transmission line with the help of the balanced condition by using the proper series capacitors and shunt inductors to produce a continuous 
transition from the left-handed to the right-handed region [14]. In contrast to CRLH based unit cells, the unit cells of periodic LWAs doesn't require subwavelength-ness $\left(P<\lambda_{\mathrm{g}} / 4\right)$ thus providing the design flexibility [15].

The LWAs require ridges to achieve backward, broadside, and forward radiation, relying on multilayer substrates for fabrication purposes [16-18]. Recently, a planar SIW based LWA is proposed for the suppression of OSB using the impedance matching technique [19], [20]. Very few planar structures in literature have been proposed for the SIW LWA with OSB suppression according to the best of author's knowledge [6], [19], [20]. The work is different from that of the planar SIW LWA as this study uses the RC technique and the asymmetric technique for complete OSB suppression and radiation efficiency equalization through broadside for the planar SIW LWA [19], [20].

In this paper, firstly, the mitigation of OSB using RC technique has been discussed and validated with the help of single and double slot designs of SIW LWAs. Secondly, the asymmetric design is developed for complete OSB suppression and radiation efficiency equalization through broadside with seamless beam scanning from backward to forward direction $\left(-32^{\circ}\right.$ to $\left.+27^{\circ}\right)$ achieving consistent gain $\sim 12.5 \mathrm{dBi}$ for 11 unit cells. $\mathrm{RC}$ and asymmetric techniques have been implemented for the first time in SIW LWA as per author's knowledge.

The remainder of the paper is organized as follows: In Sec. 2, two structures of proposed periodic LWA are designed and simulated for the discussion of the RC technique to mitigation the OSB by analyzing the Bloch impedance behavior. Section 3 discusses the total OSB closure and radiation efficiency improvement as well as equalization through broadside for asymmetrical design in comparison to symmetrical double slot design. Section 4 shows the fabricated prototype and measured results for the developed asymmetrical leaky wave structure and Section 5 draws the conclusion.

\section{Mitigation of Open Stop Band}

In $\mathrm{RC}$ technique, a unit cell consists of two slot pairs which are spaced by a distance of $\sim \lambda_{\mathrm{g}} / 4$. Reflections from one slot are cancelled out by reflections generating from the other slots. At the frequencies of broadside radiation, the reflected waves of each unit cell are in phase, and hence no EM power is fed into the LWA for broadside radiation. Consequently in 1-D periodic LWA containing only one radiating element, power is partially reflected back towards the source from the slot. The phase difference between the adjacent slots in the periodic LWA of single slot design at broadside is

$$
\Delta \varphi=\beta_{0} P=2 \pi
$$

where $\beta_{0}$ is the fundamental space harmonic, $P$ is the period of the unit cell. Hence the reflected waves from each slot are in phase. If the identical second radiating element is introduced in the unit cell then according to RC technique definition [9]

$$
2 \beta_{0} S d x=\pi
$$

This means that at the stop-band frequency, the reflected waves from the two slots within unit cell are nearly cancelled, where $S d x$ is the center to center distance between the two radiating elements in $\mathrm{x}$-direction. Therefore, the second radiating element in the unit cell is introduced at a quarter distance from the first slot providing only mitigation of OSB

$$
\frac{S d x}{P}=\frac{1}{4}
$$

For the implementation of the RC technique in SIW LWAs, two configurations of single slot and double slot designs are shown in Fig. 1. Both the structures are designed on the Rogers 5880 with a permittivity of 2.2 , a loss tangent of 0.001 and a thickness of $0.787 \mathrm{~mm}$. The cross slots are etched on the top side of the SIW providing radiations in the space. The slot impedance should be matched with free space impedance for efficient radiation. Generally a 1-D periodic LWA is designed in such a way that the radiation is occurring either from $n=-1$ or 0 (CRLH LWA) space harmonic [2]. In the presented structures, fast wave spatial harmonic $n=-1$ is chosen which is generated using periodic perturbation of cross slots along the axial line of basic structure. According to Bloch-Floquet's theory, periodic structure supports infinite number of space harmonics given by [7]

$$
\beta_{n}=\beta_{0}+\frac{2 \pi n}{P} .
$$

The design starts with determining the unit cell period by using (1). The phase constant for the unperturbed SIW for $\mathrm{TE}_{10}$ fundamental mode can be deduced as in [19] by using (5)

$$
\beta_{0}=\sqrt{\varepsilon_{\mathrm{r}} k_{0}^{2}-\left[\frac{\pi}{w_{\mathrm{eff}}}\right]^{2}} .
$$

The narrow beam of these antennas can point either in backward or forward directions in space, depending on the value of free space wave number $k_{0}$ according to (6)

$$
\sin \theta=\frac{\beta}{k_{0}} .
$$

where $\theta$ is the main beam angle, measured from the broadside direction. The length of the LWA is selected such that $90 \%$ of its power is radiated along the length before reaching its load. The width of the SIW is designed according to the (7), such that the proposed structure operates for $\mathrm{Ku}$ band [21]

$$
w_{\text {eff }}=w-1.08 \frac{D^{2}}{S}+0.1 \frac{D^{2}}{w}
$$

where $w_{\text {eff }}$ is the effective width of the SIW, $w$ is the equivalent rectangular waveguide width, $D$ is the diameter of the 


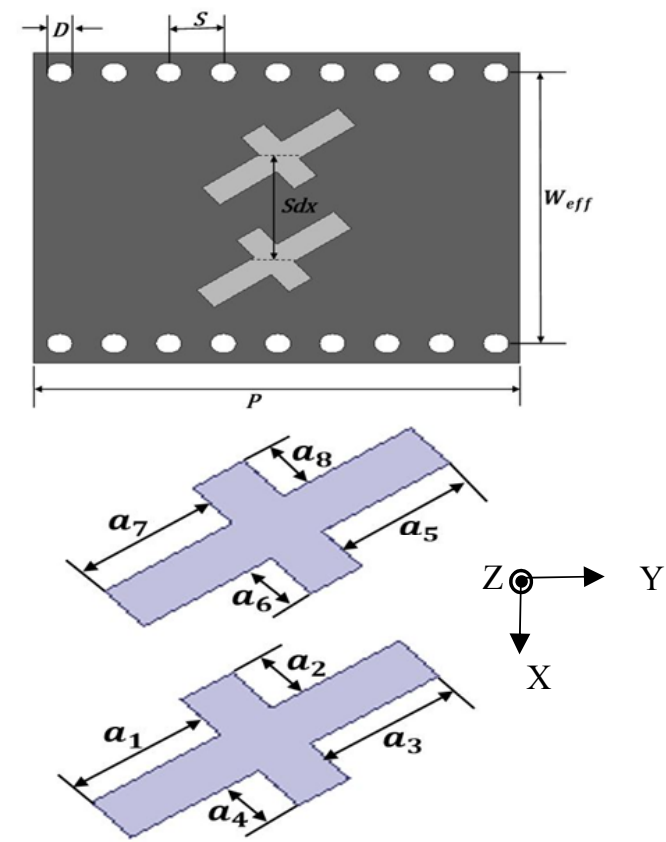

(a)

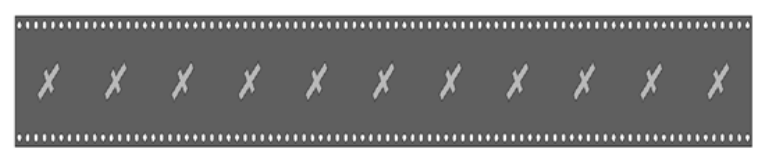

(b)

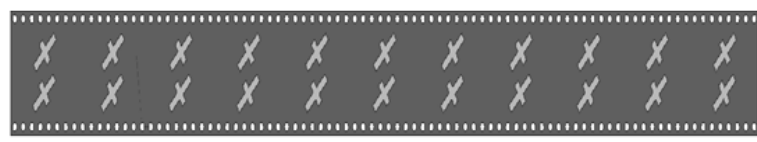

(c)

Fig. 1. (a) Double slot design unit cell and its slot dimensions. (b) Single slot LWA. (c) Double slot LWA.

vias and $S$ is the center to center distance between the vias. The cross slot used in the designs consists of longitudinal and transversal components for continuous beam scanning [22]. Initially the slots are designed according to our broadside frequency $(14.6 \mathrm{GHz})$ and their lengths are taken as $\lambda_{\mathrm{b}} / 4$ and $\lambda_{\mathrm{b}} / 8$ for transverse and longitudinal direction respectively, and width of the slot is taken as $\sim \lambda_{\mathrm{b}} / 20$ where $\lambda_{\mathrm{b}}$ is the wavelength at broadside frequency. The width of the slot is taken as $b$ and is same for both the slots.

In an infinite periodic structure with a symmetrical unit-cell, the input impedance of the antenna at the source is the Bloch impedance of the unit-cell $Z_{\mathrm{B}}$. Therefore, the input reflection coefficient of the antenna is given by (8)

$$
\Gamma_{\text {in }}=\frac{Z_{\mathrm{B}}-Z_{0}}{Z_{\mathrm{B}}+Z_{0}} .
$$

Further optimizations has been performed for $S d x$ to achieve $\Gamma_{\text {in }}=0$. Both the designs are simulated using Ansys HFSS software and simulation results show the existence and mitigation of the OSB in the single and double slot design respectively, hence verifying the $\mathrm{RC}$ technique for the SIW LWA.

The mitigation of the OSB effects in this study is related to the real part of the Bloch impedance. The real parts of the Bloch impedance are plotted in Fig. 2 for both the designs using (9) [12]

$$
\begin{gathered}
Z_{\mathrm{B}}=-\frac{\tau}{Y_{\mathrm{sh}}}+\sqrt{\frac{\tau^{2}}{Y_{\mathrm{sh}}}+\frac{Z_{\mathrm{se}}}{Y_{\mathrm{sh}}}} \\
T=\sqrt{\frac{\left(Y_{21}-Y_{11}\right)}{\left(Y_{21}-Y_{22}\right)}}, \\
\tau=\frac{1}{2}\left(T^{2}-\frac{1}{T^{2}}\right) .
\end{gathered}
$$

As seen from Bloch impedance curves, mismatching of atbroadside Bloch impedance and off-broadside Bloch impedance is significant in the case of single slot design compared to double slot design. Hence there exists the greater band of frequency in OSB region. The mitigation of OSB effects for the double slot is readily observed with a characteristics as predicted by the Bloch impedance, full wave analysis of the structure has been performed and corresponding plot of reflection coefficient $\left(S_{11}\right)$ is shown in Fig. 3. For the single slot design, an OSB of $2.5 \mathrm{GHz}$ compared to $0.9 \mathrm{GHz}$ for the double slot design is observed. This validates the mitigation of OSB using RC technique.

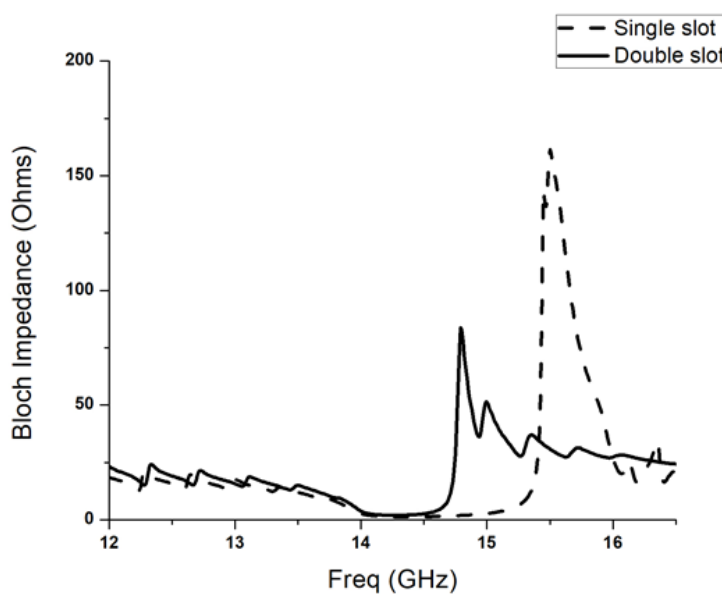

Fig. 2. Bloch impedance of single and double slot designs.

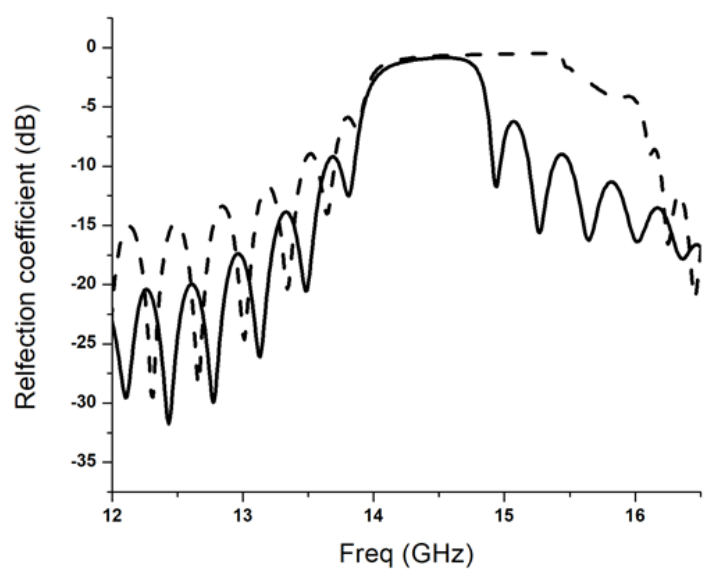

Fig. 3. Comparison of reflection coefficient for single (dash) and double slot design (solid). 


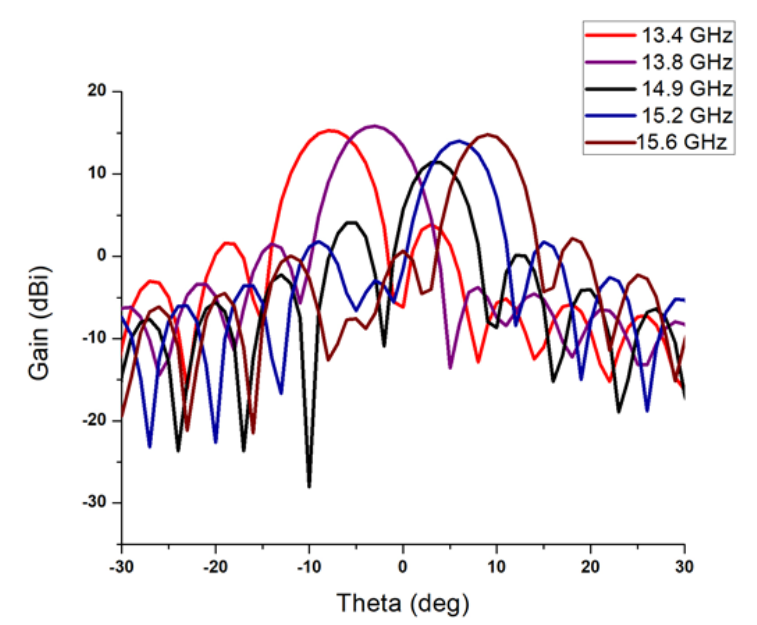

Fig. 4. Gain in $\mathrm{dBi}$ as a function of theta for double slot design.

\begin{tabular}{|c|c|c|c|}
\hline Parameters & $\begin{array}{c}\text { Single slot } \\
(\mathbf{m m})\end{array}$ & $\begin{array}{c}\text { Double slot } \\
(\mathbf{m m})\end{array}$ & $\begin{array}{c}\text { Asymmetric } \\
(\mathbf{m m})\end{array}$ \\
\hline$P$ & 16.91 & 17 & 17 \\
\hline$W_{\text {eff }}$ & 12.54 & 12.54 & 12.54 \\
\hline$D$ & 1 & 1 & 1 \\
\hline$S$ & 2 & 2 & 2 \\
\hline$S d x$ & - & 2.38 & 2.38 \\
\hline$b$ & 1 & 1 & 1 \\
\hline$a_{1}$ & 3 & 3 & 4 \\
\hline$a_{2}$ & 1.5 & 1.5 & 3.089 \\
\hline$a_{3}$ & 3 & 3 & 3 \\
\hline$a_{4}$ & 1.5 & 1.5 & 1.5 \\
\hline$a_{5}$ & - & 3 & 4.21 \\
\hline$a_{6}$ & - & 1.5 & 3 \\
\hline$a_{7}$ & - & 3 & 3 \\
\hline$a_{8}$ & - & 1.5 & 1 \\
\hline
\end{tabular}

Tab. 1. Parameters of the all the designs.

In Fig. 4, the input gain as a function of theta for double slot design is plotted confirming the radiation degradation near the broadside region. The input gain at the broadside frequency has dropped to $10 \mathrm{dBi}$ since the matching is poor. This is in accordance with the mismatch of the Bloch impedance at broadside frequency $(14.9 \mathrm{GHz})$. The broadside frequencies of both the designs are different because of the implementation of the RC technique. Both the frequencies lie in the Ku band. Though the OSB is significantly mitigated with respect to (w.r.t) the single slot design, continuous beam scanning with constant gain and efficiency equalization through broadside is not obtained. Specifically at OSB frequency $(14.9 \mathrm{GHz})$, the gain is decreased by about $4 \mathrm{dBi}$, while the return loss shows a noticeable mismatch. To overcome the drawbacks of mitigate on and radiation degradation in the double slot design, asymmetry technique is applied which is shown in the next section. The optimized parameters for all the design cases considered in this study are shown in Tab. 1.

\section{Total OSB Closure and Radiation Efficiency Equalization}

In this case, the SIW LWAs consist of resonant elements, broadside frequency coincides with the resonance frequency of the structure. In this situation, $Z_{\mathrm{B}}$ becomes exclusively dependent on the losses of the structure [23]. In [12], the authors studied the broadside effect by using a general equivalent circuit consisting of a lattice network with a series LC-resonator in the series branch and a shunt LC-resonator in the cross branch. With this model, the broadside effect at the resonance frequencies of the structure can be easily understood and shows that Bloch impedance depends heavily on the losses.

In this section the asymmetric technique is implemented in the double slot design for total OSB closure and radiation efficiency improvement and its equalization through broadside. The losses are controlled by varying the asymmetric parameters of the slots. The radiation efficiency improvement is explained with the help of even and odd mode analysis as in [13]. For the 1-D periodic LWA the even and odd modes should radiate efficiently in order to have high radiation efficiency. For the symmetrical designs (single and double slot) along the transversal and longitudinal plane, the even mode leaves no residual polarization which leads to low radiation efficiency. The even mode can efficiently radiate by introducing the asymmetry w.r.t transversal and longitudinal plane leaving the residual polarization.

The complete elimination of OSB effects and radiation efficiency equalization are related to the real part of the Bloch impedance. The asymmetric parameters $\left(a_{1}-a_{8}\right)$ in the design for the LWA are designed keeping in accordance with the following facts:

1. For complete suppression of OSB, the Bloch impedance should be kept real for the desired range in the periodic LWAs [11].

2. The at-broadside and off-broadside Bloch impedances must be matched in order to have radiation efficiency equalization through broadside in periodic LWAs [12].

The unit cell and the array for asymmetric designs are shown in Fig. 5. The dispersion diagram is plotted with the help of (12) as shown in Fig. 6

$$
\beta=\frac{a \cos \left(\left(1-S_{11} S_{22}\right)+\left(S_{12} S_{21}\right)\right)}{2 S_{21}} .
$$

It is clearly apparent from the dispersion diagrams that the OSB has been eliminated compared to the double slot design with a broadside frequency of $14.6 \mathrm{GHz}$ lying in the Ku-band. The unit cell has been optimized to achieve the frequency balancing condition. 


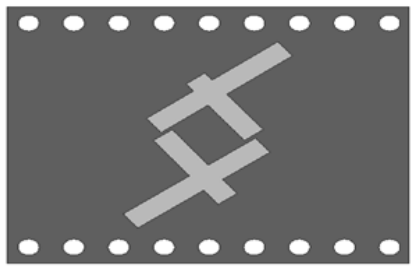

(a)

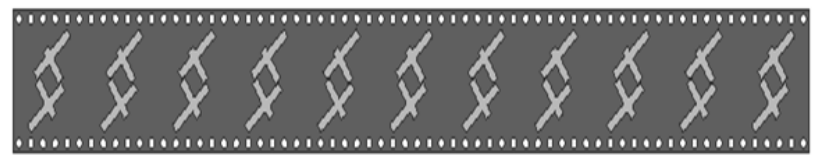

(b)

Fig. 5. (a) Unit cell design. (b) Proposed Asymmetrical LWA.

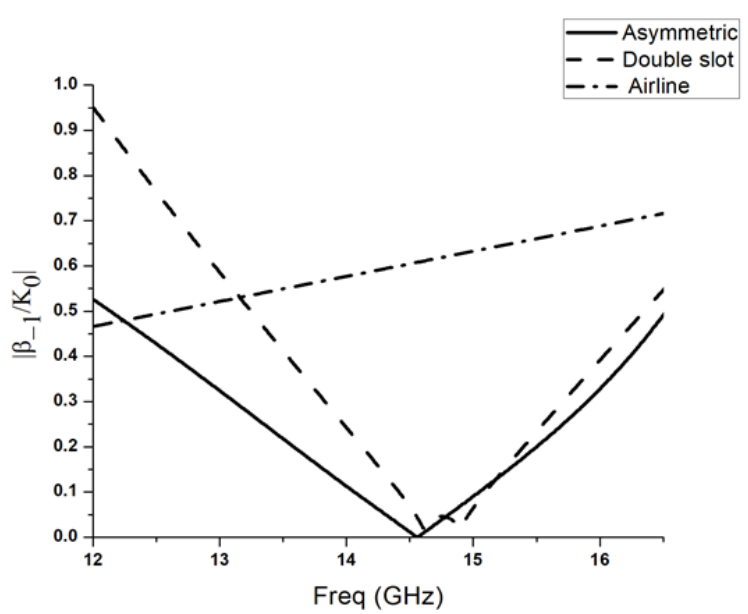

Fig. 6. Dispersion diagram for asymmetric and double slot design.

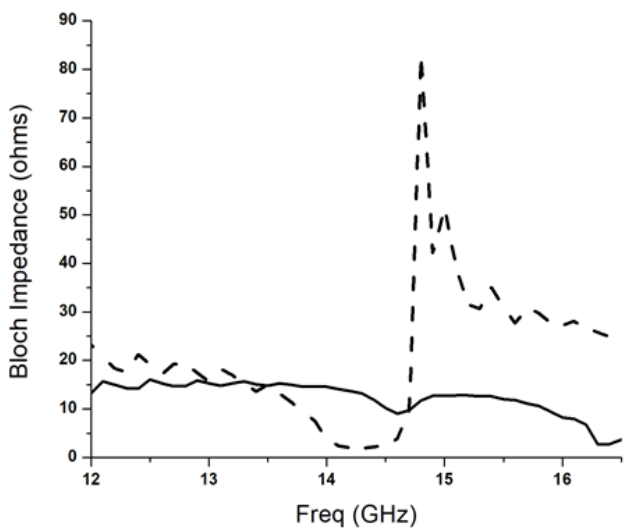

Fig. 7. Bloch impedance for both double slot (dash) and asymmetric (solid) designs.

For the radiation efficiency equalization through broadside, full wave analysis of the structure has been performed and it is optimized to match the at-broadside Bloch impedance and off-broadside Bloch impedance. The real parts of the Bloch impedance are using (9). The double slot design has been optimized for the parameters which control the asymmetry $\left(a_{1}-a_{8}\right)$. Figure 7 shows the real part of the Bloch impedance for both the double slot and asymmetrical designs. The double slot has a real part almost equal to zero at the vicinity of broadside. The asymmetric

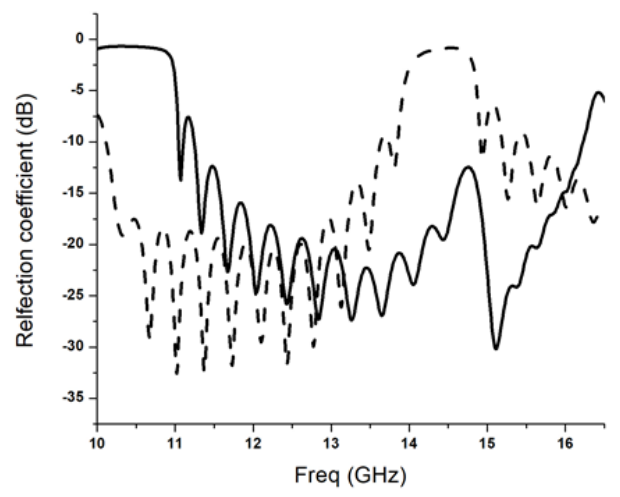

Fig. 8. Comparison of reflection coefficient for double slot (dash) and asymmetric (solid) design.

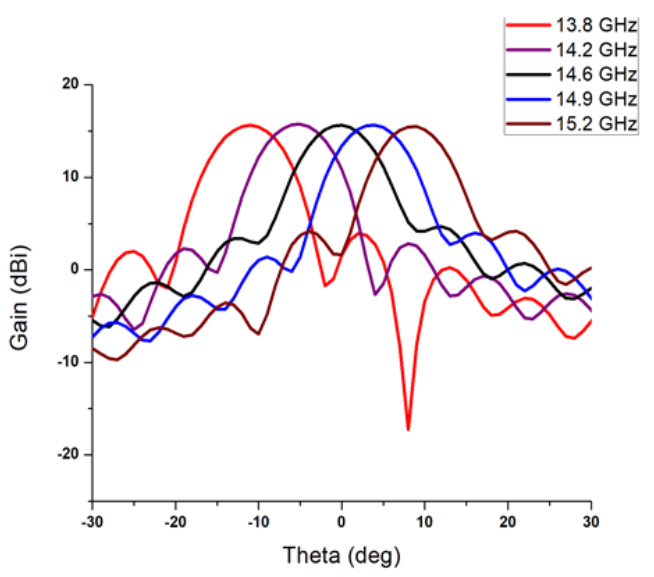

Fig. 9. Gain in $\mathrm{dBi}$ as a function of theta for asymmetric design.

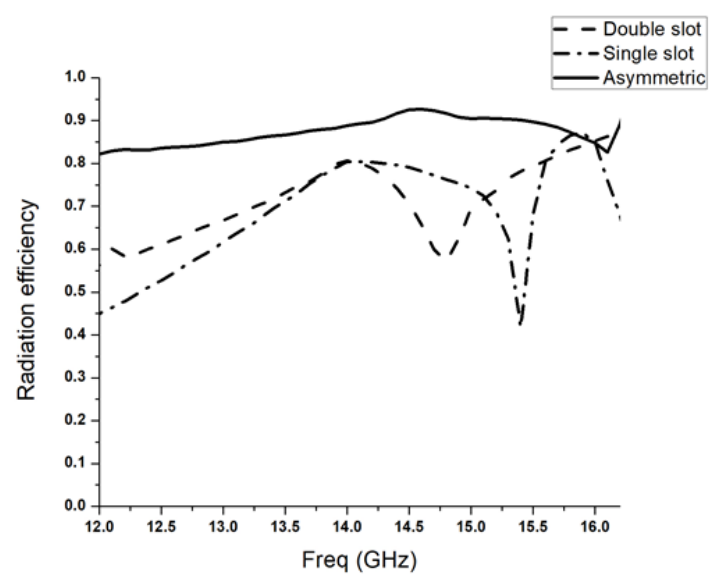

Fig. 10. Radiation efficiency comparison.

design compared to double slot design has a real part at broadside as well as it is almost equalized through broadside. Bloch impedance analysis method is particularly efficient and easy for periodic structure provided that a full wave analysis is available.

In order to validate, reflection coefficient $\left(S_{11}\right)$ and input gain curves are plotted shown in Fig. 8 and Fig. 9. The reflection coefficient $\left(S_{11}\right)$ for the asymmetric design is significantly below compared to double slot design particularly at broadside frequency. As a result of total OSB 
closure and radiation efficiency equalization the constant gain of $\sim 12.5 \mathrm{dBi}$ is achieved which is evident from the gain curves. The radiation efficiency curves for the three designs are plotted in Fig. 10. It is readily observed that the radiation efficiency is improved as well as it is equalized through broadside. The radiation efficiency for the asymmetric design is $\sim 85 \%$.

\section{Results and Discussions}

For verification purpose, fabricated asymmetrical structure is shown in Fig. 11 of the proposed LWA designed in Sec. 3. This prototype is fed by SMA connectors through microstrip-to-SIW transitions. The prototype is fabricated using Rogers $5880\left(\varepsilon_{\mathrm{r}}=2.2\right)$. The $\mathrm{S}_{11}$-parameters are measured using a microwave vector network analyzer (VNA), and the results are depicted in Fig. 12 together with the simulation results (from Ansys HFSS). The parameters are all lower than $-10 \mathrm{~dB}$ in the $12 \mathrm{GHz}$ to $16.5 \mathrm{GHz}$ frequency range. Due to additional reflections caused by the SMA connectors, the measured $\mathrm{S}_{11}$ spectrum differs.

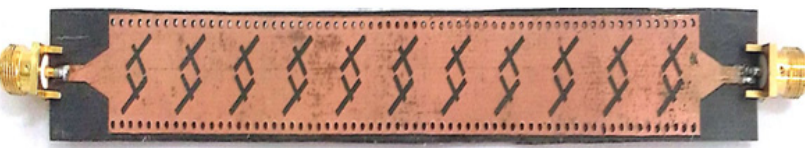

Fig. 11. Fabricated prototype of asymmetrical LWA.

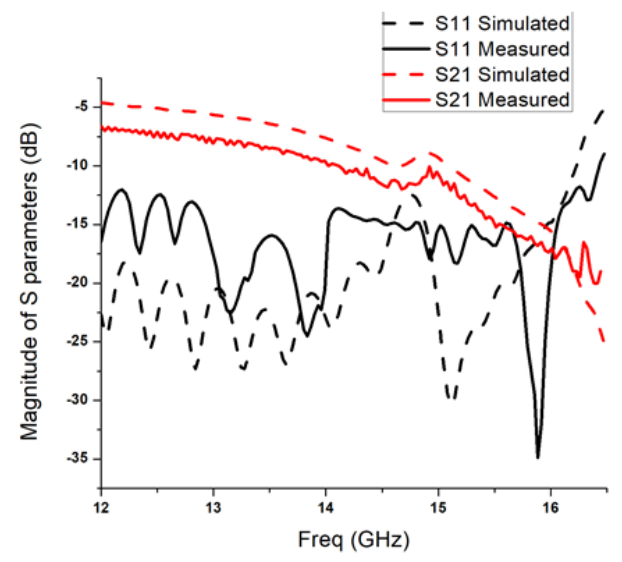

Fig. 12. Simulated and measured $S_{11} \& S_{21}$ - parameters.

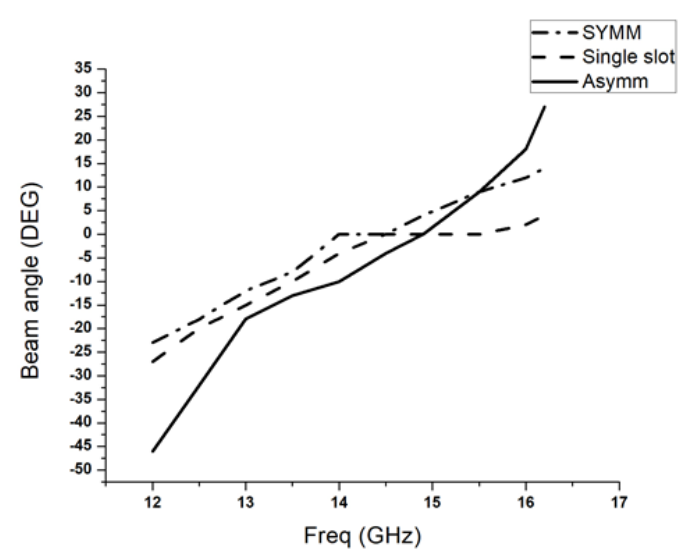

Fig. 13. Beam angle comparison for all the designs.

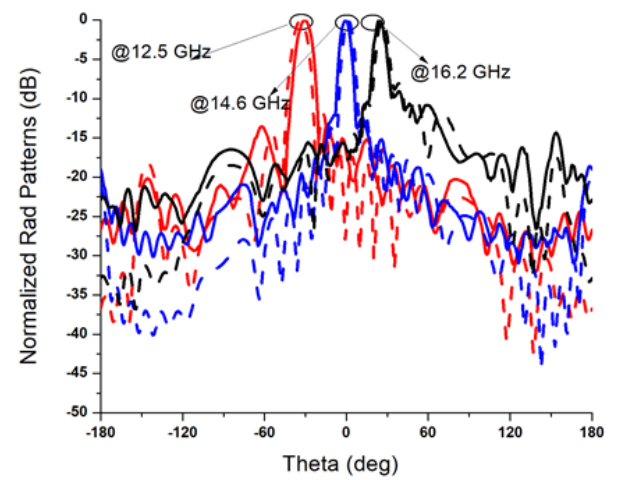

(a)

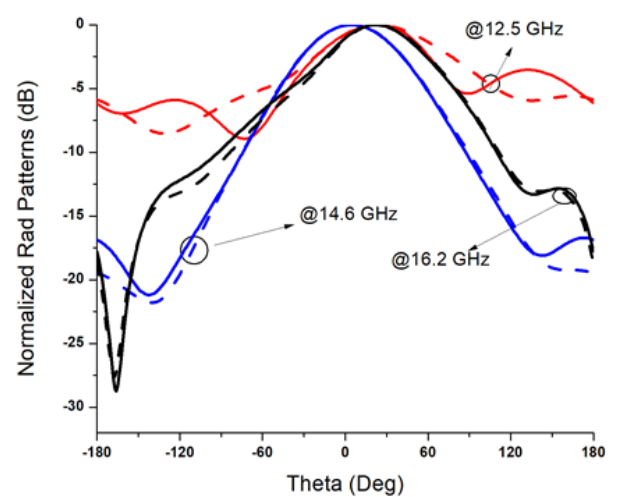

(b)

Fig. 14. (a) Simulated (dotted) and measured (solid) normalized E-plane (Y-Z plane) radiation patterns at different frequency. (b) Simulated (dotted) and measured (solid) normalized $\mathrm{H}$-plane $(\mathrm{X}-\mathrm{Z}$ plane) radiation patterns at different frequency.

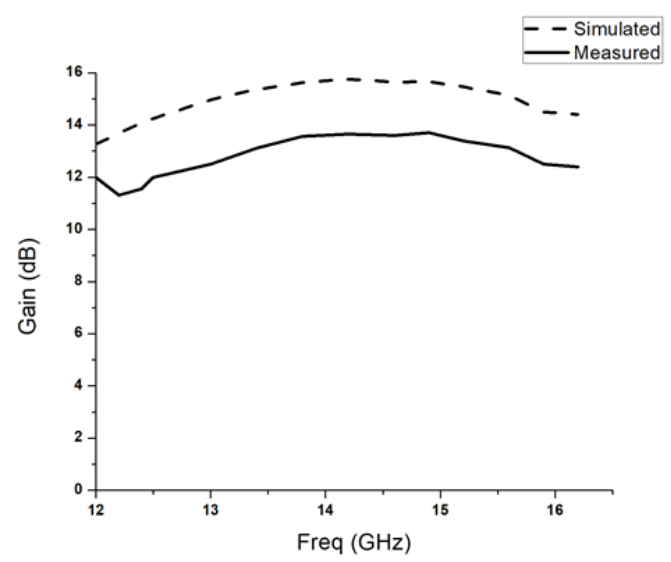

Fig. 15. Simulated and measured gain patterns.

The main lobe directions for all designs are compared in Fig. 13. The scanning range for the asymmetric design is better than single and double slot design. Also the mitigation and suppression of OSB can also be observed from the beam angle curves. Figure 14 presents the experimental radiation patterns measured through a far-field measurement system in an anechoic chamber. The far-field radiation pattern of this antenna indicates a directional patterns characteristic in E plane (Y-Z). Both E-plane and H-plane radiation patterns at $12.5 \mathrm{GHz}, 14.6 \mathrm{GHz}$ (broadside) and 16.2 GHz are shown in Fig. 14 (a), (b). The well agreed 
measured and simulated results demonstrate that the main radiation beam of the prototype scans from $-32^{\circ}$ at $12.5 \mathrm{GHz}$ to $+27^{\circ}$ at $16.2 \mathrm{GHz}$ with smooth transition through broadside at $14.6 \mathrm{GHz}$. The E-and H-plane patterns constitute a frequency-dependent scanning, with maximum radiation in the broadside. The measured and simulated gain is depicted in Fig. 15. The constant gain realized for the scanning range for the prototype is $\sim 12.5 \mathrm{dBi}$. The constant gain is attributed to the Bloch impedance and radiation efficiency equalization through broadside.

\section{Conclusion}

A planar asymmetric SIW LWA is proposed for the $\mathrm{Ku}$ band capable of continuous beam scanning with total OSB closure and radiation efficiency equalization. Two structures; single and double slot are designed for the discussion of RC technique and mitigation of OSB in double slot design is presented. Asymmetry is introduced in the double slot design for complete suppression of OSB and radiation efficiency equalization and improvement. Results show that both RC and asymmetric techniques can be applied for SIW LWAs for total OSB closure, and radiation efficiency improvement and equalization through broadside. The prototype proposed provides a continuous beam scanning from $-32^{\circ}$ to $+27^{\circ}$ with constant gain of $\sim 12.5 \mathrm{dBi}$ with efficiency of $\sim 85 \%$. The implementation of asymmetric technique in SIW LWAs can further be exploited in designing dispersion sensitive LWAs.

\section{Acknowledgement}

This work is supported by the Defence Research \& Development Organization (DRDO) of India Grant ERIP/ER/1403170/M/01/1555. The authors also thank the reviewers for their valuable comments.

\section{References}

[1] JACKSON, D. R., CALOZ, C., ITOH, T. Leaky-wave antennas. Proceedings IEEE, 2012, vol. 100, no. 7, p. 2194-2206. DOI: 10.1109/JPROC.2012.2187410

[2] OLINER, A., JACKSON, D. R. Leaky-wave antennas. In Antenna Engineering Handbook. Ed. J. L. Volakis. New York: McGrawHill, 2007. DOI: 10.1002/9780470294154.ch7

[3] LIU, J., TANG, X., LI, Y., et.al. Substrate integrated waveguide leaky-wave antenna with $\mathrm{H}$-shaped slots. IEEE Transactions on Antennas and Propagation, 2012, vol. 60, no. 8, p. 3962-3967. DOI: $10.1109 /$ TAP.2012.2201085

[4] NASIMUDDIN, N., CHEN, Z. N., QING, X. Substrate integrated metamaterial-based leaky-wave antenna with improved boresight radiation bandwidth. IEEE Transactions on Antennas and Propagation, 2013, vol. 61, no. 7, p. 3451-3457. DOI: 10.1109/TAP.2013.2256094

[5] LIU, J., JACKSON, D. R., LONG, Y. Substrate integrated waveguide (SIW) leaky-wave antenna with transverse slots. IEEE
Transactions on Antennas and Propagation, 2012, vol. 60, no. 1, p. 20-29. DOI: 10.1109/TAP.2011.2167910

[6] HENRY, R., OKONIEWSKI, M. A broadside scanning substrate integrated waveguide periodic phase-reversal leaky-wave antenna. IEEE Antennas and Wireless Propagation Letters, 2016, vol. 15, p. 602-605. DOI: 10.1109/LAWP.2015.2462733

[7] HESSEL, A., COLlin, R. E., ZUCKER, R. F. (Eds.) Antenna Theory, Part II. New York: McGraw-Hill, 1969, ch. 19. ISBN-13: 978-0070118003

[8] JACKSON, D. R., OLINER, A. Leaky wave antennas. In Modern Antenna Handbook. Ed. C. A. Balanis, ch. 7. Wiley-Interscience, 2008. ISBN: 978-0-470-03634-1

[9] GUGLIELMI, M., JACKSON, D. R. Broadside radiation from periodic leaky-wave antennas. IEEE Transactions on Antennas and Propagation, 1993. vol. 41, no. 1, p. 31-37. DOI: $10.1109 / 8.210112$

[10] LEE, J. H., HIRONO, T., HIROKAWA, J., et.al. A center-feed waveguide transverse slot linear array using a transverse-slot feed for blocking reduction. In IEEE Antennas Propagation Society AP$S$ International Symposium. San Diego (CA, USA), 2008, p. 1-4. DOI: 10.1109/APS.2008.4619808

[11] PAUlOTTO, S., BACCARELli, P., FREZZA, F., et.al. A novel technique for open-stopband suppression in 1-D periodic printed leaky-wave antennas. IEEE Transactions on Antennas and Propagation, 2009, vol. 57, no. 7, p. 1894-1906. DOI: 10.1109/TAP.2009.2019900

[12] OTTO, S., AL-BASSAM, A., RENNING, A., et.al. Transversal asymmetry in periodic leaky-wave antennas for Bloch impedance and radiation efficiency equalization through broadside. IEEE Transactions on Antennas and Propagation, 2014, vol. 62, no. 10, p. 5037-5054. DOI: 10.1109/TAP.2014.2343621

[13] TANG, X. L., ZHANG, Q., HU, S., ZHUANG, Y., et al. Continuous beam steering through broadside using asymmetrically modulated Goubau line leaky-wave antennas, Scientific Reports, 2017, vol. 7, p. 1-8. DOI: 10.1038/s41598-017-12118-8

[14] CALOZ, C., ITOH, T. Electromagnetic Metamaterials: Transmission Line Theory and Microwave Applications: The Engineering Approach. Hoboken, NJ: Wiley, 2006. ISBN: 978-0471-66985-2

[15] CALOZ, C., LAI, A., ITOH, T. The challenge of homogenization in metamaterials. New Journal of Physics, 2005, vol. 7, art. no. 167, 15 p. DOI: 10.1088/1367-2630/7/1/167

[16] MALLAHZADEH, A., MOHAMMAD-ALI-NEZHAD, S. Long slot ridged SIW leaky wave antenna design using transverse equivalent technique. IEEE Transactions on Antennas and Propagation, 2014, vol. 62, no. 11, p. 5445-5452. DOI: 10.1109/TAP.2014.2353673

[17] MALLAHZADEH, A., MOHAMMAD-ALI-NEZHAD, S. Periodic ridged leaky-wave antenna design based on SIW technology. IEEE Antennas and Wireless Propagation Letters, 2015, vol. 14, p. 354-357. DOI: 10.1109/LAWP.2014.2361175

[18] DONG, X., WANG, H., XEU, F., et.al. Design and measurement of a novel seamless scanning leaky wave antenna in ridge gap waveguide technology. Progress In Electromagnetics Research M, 2017, vol. 58, p. 147-157. DOI: 10.2528/PIERM17051801

[19] LYU, Y., LIU, X., WANG, P., et al. Leaky-wave antennas based on non-cutoff substrate integrated waveguide supporting beam scanning from backward to forward. IEEE Transactions on Antennas and Propagation, 2016, vol. 16, no. 6, p. 2155-2164. DOI: 10.1109/TAP.2016.2550054

[20] LYU, Y., LIU, X., WANG, P., et al. Periodic SIW leaky-wave antenna with large circularly polarized beam scanning range. IEEE Transactions on Antennas and Propagation, 2017, vol. 64, p. 2493-2496. DOI: 10.1109/LAWP.2017.2726089

[21] XU, F., WU, K. Guided-wave and leakage characteristics of substrate integrated waveguide. IEEE Transactions on Microwave 
Theory and Technique, 2005, vol. 53, no. 1, p. 66-73. DOI: 10.1109/TMTT.2004.839303

[22] PAULOTTO, S., BACCARELLI, P., FREZZA, F. et al. Full-wave modal dispersion analysis and broadside optimization for a class of microstrip. IEEE Transactions on Microwave Theory and Technique, 2008, vol. 56, no. 12, p. 2826-2837. DOI: 10.1109/TMTT.2008.2007333

[23] OTTO, S., RENNINGS, A., SOLBACH, K., et al. Transmission line modeling and asymptotic formulas for periodic leaky-wave antennas scanning through broadside. IEEE Transactions on Antennas and Propagation, 2011, vol. 59, no. 10, p. 2493-2496. DOI: 10.1109/TAP.2011.2163781

\section{About the Authors ...}

Rahul AGRAWAL (corresponding author) was born in Guna (M.P). He received his B.Tech (Electr. Comm. Eng.) from RGPV, Bhopal and his M.Tech from DIT University, Dehradun. Currently he is a working as a Senior Research Fellow for DRDO funded project in DIT University, Dehradun. His research interests include: transmission lines
(CRLH), leaky wave antenna, electronic scanning and SIW.

Pravesh BELWAL was born in Chamba (Uttarakhand). He received his B.Tech (Electr. Comm. Eng.) from UPTU, Lucknow and his M.Tech from DIT University, Dehradun. Currently he is a Research Fellow in DIT University, Dehradun. His research interests include: half mode SIW, electronic beam scanning of LWA.

Suresh GUPTA was born in Delhi. He received his M.Tech from IIT Bombay and Ph.D. from IIT Roorkee in 1971. After putting a service of 34 years in IIT Roorkee, presently he is working as a Prof. and Dean (PG) at DIT University, Dehradun. He has supervised number of M.tech and Ph.D, students and published around 150 research papers in various journals and international conferences in the area of antenna and microwave engineering. He has also supervised the DRDO project on Development of Stealth materials and technology in IIT Roorkee. Currently, he is supervising the DRDO project at DIT University as principal investigator in the advanced leaky wave antenna field. 